\title{
Pectin-Coated Plasmonic Nanoparticles for Photodynamic Therapy: Inspecting the Role of Serum Proteins
}

\author{
José S. Cisneros, Cecilia Y. Chain,* María B. Rivas Aiello, Julieta Parisi, Daniel C. Castrogiovanni, \\ Gabriela N. Bosio, Daniel O. Mártire, and María E. Vela
}

Cite This: ACS Omega 2021, 6, 12567-12576

Read Online

ACCESS |

山ll Metrics \& More

回国 Article Recommendations

SI Supporting Information

ABSTRACT: Plasmonic metal nanoparticles (NPs) can be used as enhancers of the efficiency of standard photosensitizers (PSs) in photodynamic therapy (PDT). Protein corona, the adsorption layer that forms spontaneously around NPs once in contact with biological fluids, determines to a great extent the efficiency of PDT. In this work, we explore the possibility that pectin-coated Au NPs (Au@Pec NPs) could act as adjuvants in riboflavin (Rf)-based PDT by comparing the photodamage in HeLa cells cultured in the presence and in the absence of the NPs. Moreover, we investigate the impact that the preincubation of Rf and Au@Pec NPs (or Ag@ Pec NPs) at two very different serum concentrations could have on cell's photodamage. Because reactive oxygen species (ROS)
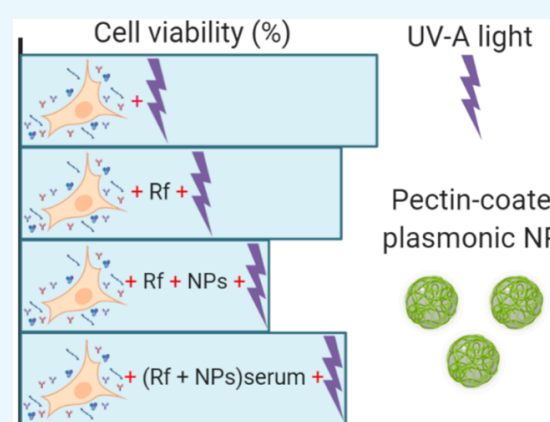

Pectin-coated plasmonic NPs
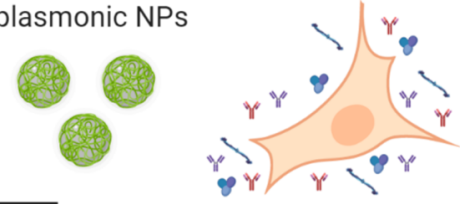
precursors are the excited states of the PS, the effect of proteins on the photophysics of Rf and Rf/plasmonic NPs was studied by transient absorption experiments. The beneficial effect of Au@Pec NPs in Rf-based PDT on HeLa cells cultured under standard serum conditions was demonstrated for the first time. However, the preincubation of Rf and Au@Pec NPs (or Ag@Pec NPs) with serum has undesirable results regarding the enhancement of Rf-based PDT. In this sense, we also verified that more concentrated protein conditions result in lower amounts of the triplet excited state of $\mathrm{Rf}$ and thus an expected lower production of ROS, which are the key elements for PDT's efficacy. These findings point out the relevance of serum concentration in the design of in vitro cell culture experiments carried out to determine the best way to combine and use potential sensitizers with plasmonic NPs to develop more effective PDTs.

\section{INTRODUCTION}

Photodynamic therapy (PDT) is based on the activation of a light-absorbing agent called the photosensitizer (PS) with light irradiation at a specific wavelength with the aim to damage the desired target, typically, cancer cells. ${ }^{1}$ PDT treatments cause cell death by apoptosis and/or necrosis due to the production of reactive oxygen species (ROS), including free radicals and singlet oxygen. The main factor governing the outcome of PDT is the interaction of the irradiated PS with cells in the target tissue or tumor. ROS have a short lifetime and act close to their site of generation; therefore, the photodamage that occurs in cells loaded with a PS and subjected to irradiation depends on the precise subcellular localization of the PS within the cell. ${ }^{2}$

Nanoparticles (NPs) represent an emerging technology in the field of PDT acting as carriers of the PS, sensitizers, energy transducers of the PS, or enhancers of ROS generation. ${ }^{3}$ Plasmonic metal NPs (Me NPs), such as silver and gold, can be used as enhancers of the photodynamic efficiency of the standard PS. ${ }^{4,5}$ Me NPs can strongly interact with neighboring molecules due to their localized surface plasmon resonance. ${ }^{6}$ These interactions can include electron transfer from excited molecules to $\mathrm{Me} \mathrm{NPs}^{7,8}$ and energy transfer from Me NPs to adjacent molecules. 9 Besides, Me NPs can affect the deactivation processes of excited molecules. ${ }^{11}$

Human plasma contains a large amount of dissolved proteins, and when NPs are injected into the body, they bind to the surface of the particles to form an adsorption layer, which has been termed "protein corona" (PC). PC alters the size, surface charge, surface composition, and functionality of NPs, giving them a completely new biological identity. ${ }^{12,13}$ Corona composition varies according to the nature of biological fluids in which NPs are dispersed, and it changes with time by slowly replacing the initial and transient kinetically controlled "soft corona" consisting of the most abundant proteins with less abundant but higher affinity proteins to form the "hard corona". ${ }^{14-18}$ These changes in the

Received: January 29, 2021

Accepted: March 29, 2021

Published: May 6, 2021

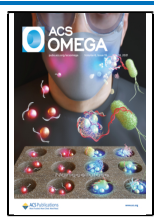


Scheme 1. Synthesis of Me@Pec NPs and Their Use as Adjuvants for the Enhancement of Rf-Based PDT
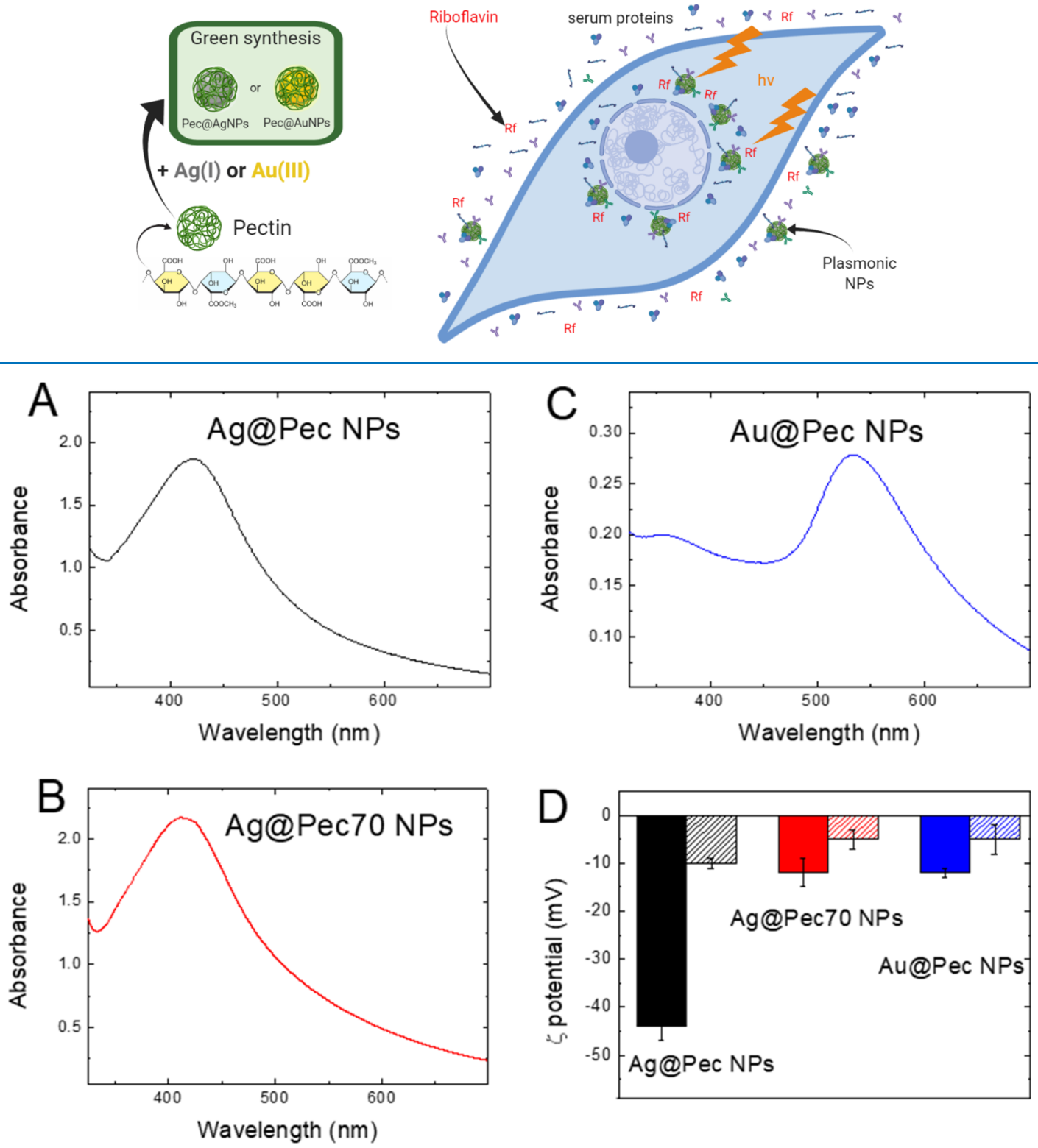

Figure 1. (A-C) UV-vis extinction spectra and (D) $\zeta$ potential (ZP) in the presence and the absence of FBS (dashed and full colored columns, respectively) of Ag@Pec NPs (black), Ag@Pec70 NPs (red), and Au@Pec NPs (blue).

PC can alter, among others, the bioavailability of NPs. Although PC has been generally considered an undesirable phenomenon as it reduces the efficiency of PDT by diminishing NPs' cellular uptake, ${ }^{16,19}$ its adsorption features have been recently exploited to load the PS chlorin e6 on the PC of gold nanorods. ROS generation upon photoirradiation of chlorin e6 adsorbed on the nanomaterial was enhanced compared to the free PS. ${ }^{20,21}$

Riboflavin (Rf), as an endogenous molecule, has the advantage over other PSs in being soluble in the physiological environment and having specific protein-mediated cellular uptake. $^{22}$ We have previously demonstrated that a 1:1 complex (Rf-Ag@Pec NPs) between Rf and pectin-coated Ag NPs ( $\mathrm{Ag} @$ Pec NPs) is formed and that the decay of the excited state of the complex Rf-Ag@Pec NPs in aqueous solution feeds the triplet excited state of $\mathrm{Rf}$, increasing the amounts of singlet oxygen and superoxide radical anions. ${ }^{23}$ This finding could lead, in turn, to beneficial effects of Ag@Pec NPs in Rf-based PDT, a hypothesis that was verified using HeLa cells incubated in $10 \%$ fetal bovine serum (FBS)-supplemented culture medium. The enhanced photodamage observed in the presence of Ag@Pec NPs seems to indicate that Rf enters into the cells complexed with the NPs. ${ }^{24}$

Encouraged by our results, we sought to further advance our studies to explore the possibility that pectin-coated Au NPs could act as adjuvants in Rf-based PDT and to investigate the impact that preincubation of Rf and pectin-coated Au NPs (or Ag NPs) with serum could have on the efficacy of the therapy. To this aim, pectin-coated gold and silver NPs were prepared and dispersed in media containing two very different serum concentrations, a high serum (HS) content close to protein concentration in blood (roughly $50 \mathrm{mg} / \mathrm{mL}$ ) and a five times lower one, in order to form different coronas. ${ }^{16}$ Then, the influence of serum content on the efficacy of Rf-based PDT in 
A

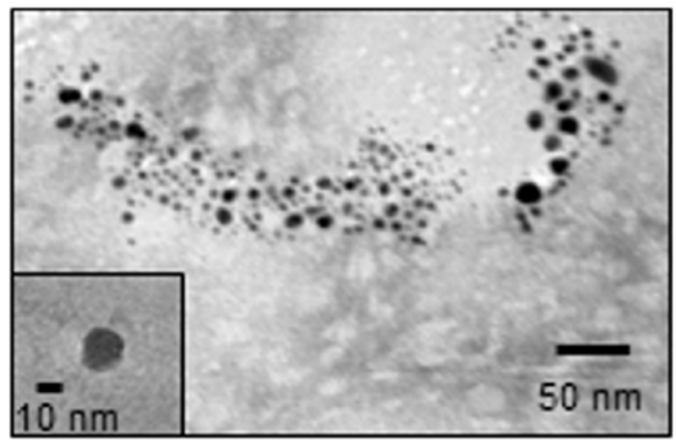

B

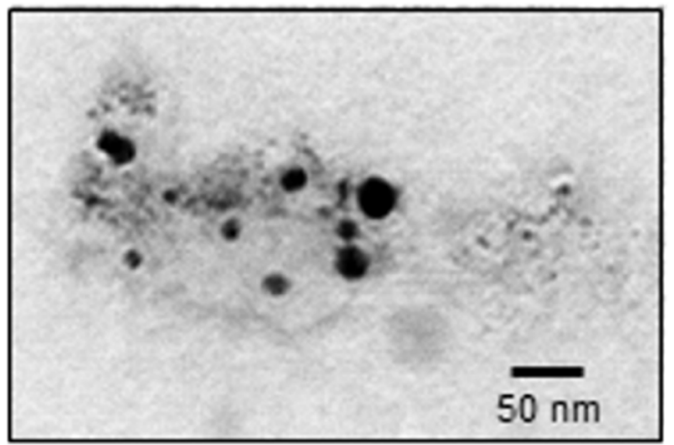

C

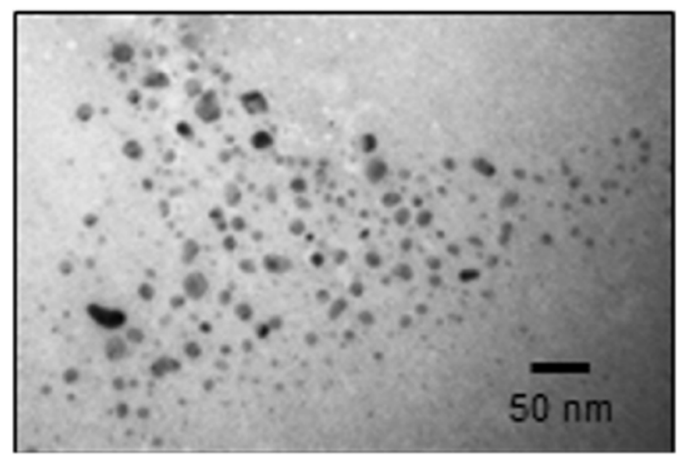

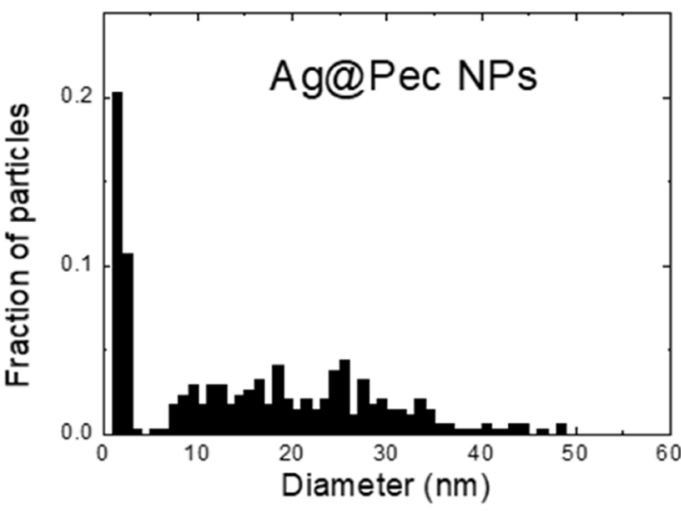
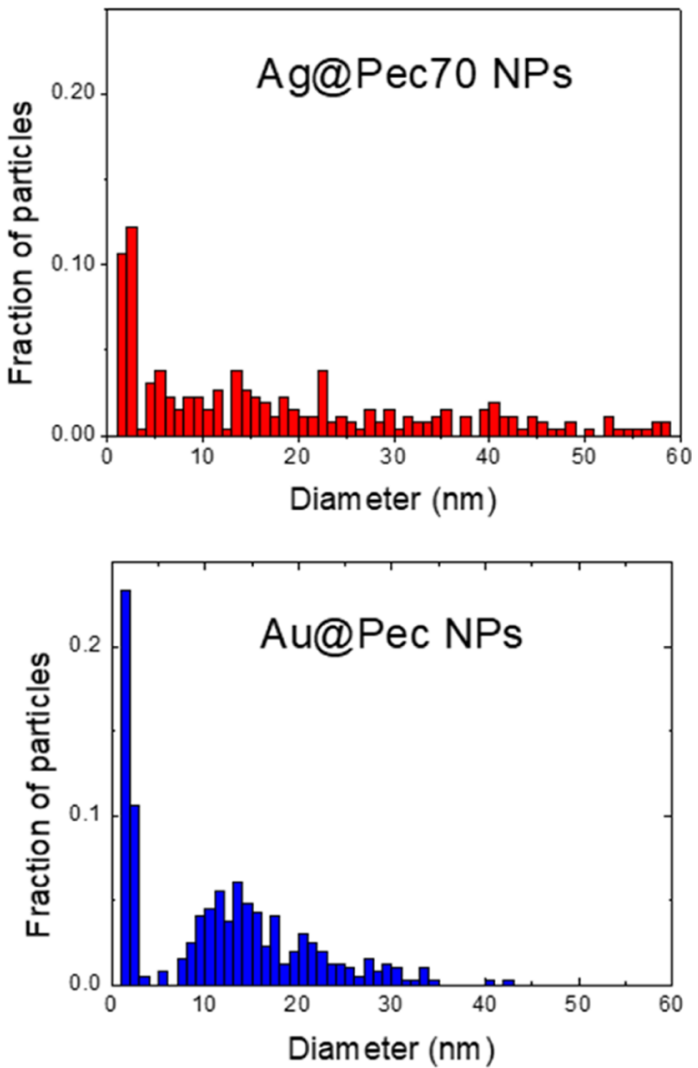

Figure 2. TEM images and size distribution of (A) Ag@Pec NPs, (B) Ag@Pec70 NPs, and (C) Au@Pec NPs.

HeLa cells with and without the assistance of pectin-coated plasmonic NPs was investigated. Because ROS precursors are the excited states of the PS, the effect of proteins on the photophysics of Rf and Rf/plasmonic NPs was studied by transient absorption experiments using bovine serum albumin (BSA) as a model protein. Hereby, we were able to highlight the relevance of serum concentration in the outcome of the in vitro phototoxicity assays carried out to develop novel and more effective PDTs.

\section{RESULTS AND DISCUSSION}

2.1. Synthesis and Characterization of Me@Pec NPs. The synthesis of Me@Pec NPs and their use as adjuvants for the enhancement of Rf-photodynamics are illustrated in Scheme 1. Pectin-coated Ag and Au NPs were synthesized by the "green" chemistry technique via chemical reduction of $\mathrm{Ag}(\mathrm{I})$ or $\mathrm{Au}(\mathrm{III})$ using pectin both as reducing and stabilizing agents. The as-prepared NPs showed broad UV-visible spectral bands (Figure 1A-C) centered at 424, 411, and 534 nm for Ag@Pec, Ag@Pec70, and Au@Pec NPs, respectively. No differences in the absorbance or in the position of the spectral bands were observed after the $30 \mathrm{~min}$ incubation of $\mathrm{Me} @ \mathrm{Pec}$ NPs with FBS, suggesting that no aggregation of the particles that could lead to precipitation or change in the size of the metallic core of the NPs occurred. Transmission electron microscopy (TEM) micrographs (Figure 2) revealed the presence of spherically shaped NPs in the synthesized $\mathrm{Me} @ P e c$ NPs, ${ }^{24}$ with a major fraction of small NPs ranging 1$2 \mathrm{~nm}$ and a nonnegligible fraction of particles with a broad distribution of sizes that ranged from 10 to $60 \mathrm{~nm}$.

TEM micrographs of Me@Pec NPs incubated with FBS only revealed the higher sized particles (Figure 3 ) that verified the colloidal stability that was previously found in other NPs with PC. ${ }^{20,21,25}$ The absence of sub-10 nm NP population in TEM images of the FBS-incubated NPs could be due to free serum proteins that hampered the observation of the smaller NPs. ${ }^{26}$ 

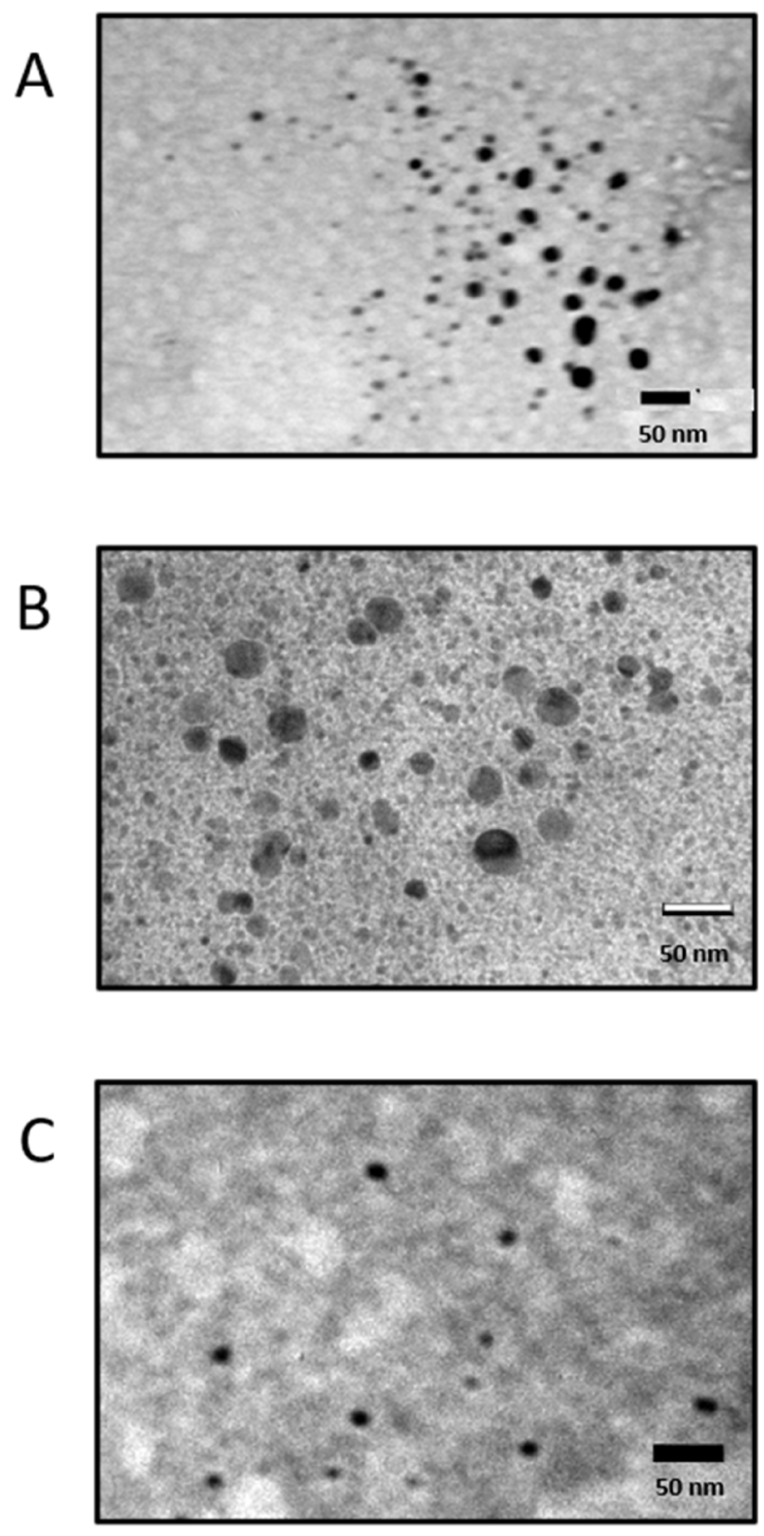
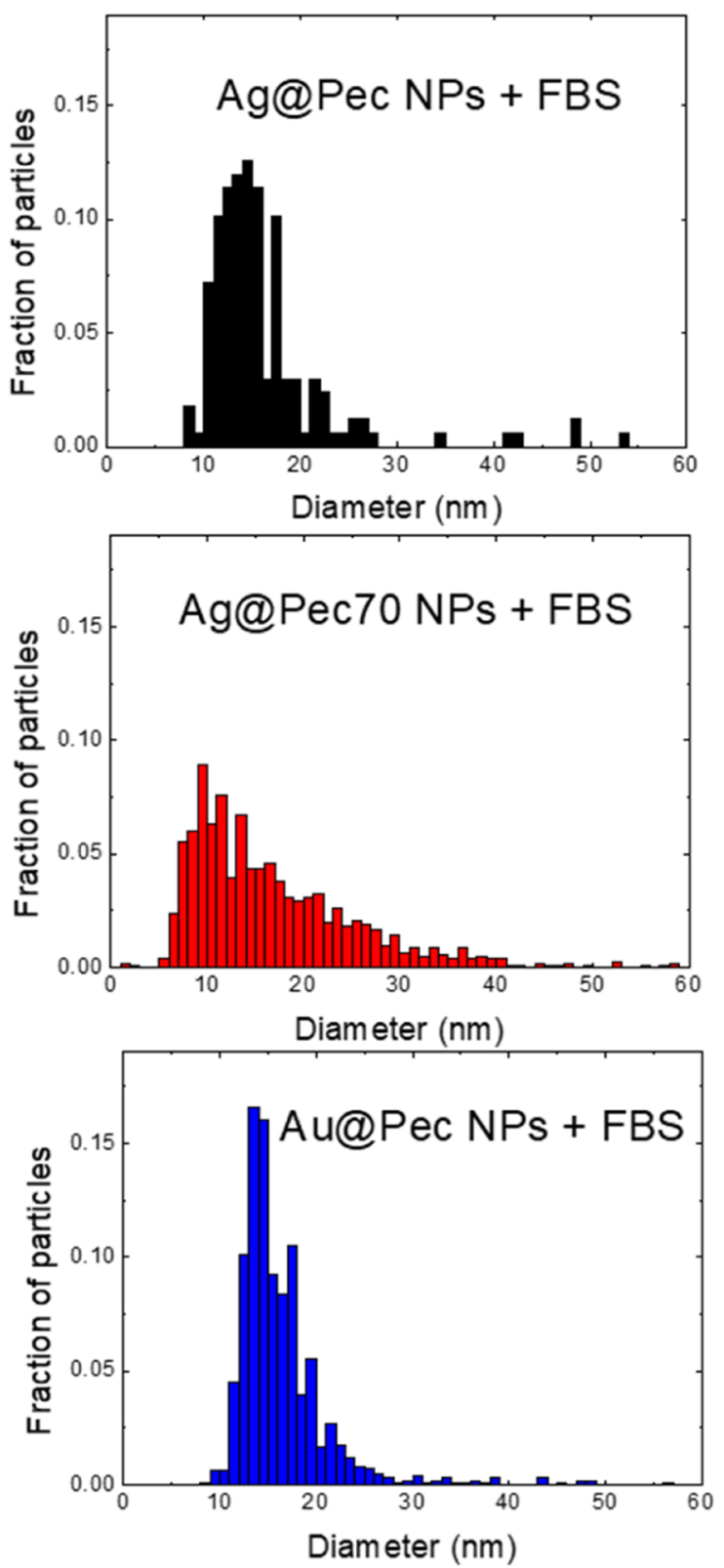

Figure 3. TEM images and size distribution of (A) Ag@Pec NPs + FBS, (B) Ag@Pec70 NPs + FBS, and (C) Au@Pec NPs + FBS.

All prepared Me@Pec NPs exhibited negative ZP in deionized water (Figure 1D).Ag@Pec NPs showed a relatively higher zeta potential of $-44 \pm 3 \mathrm{mV}$ in comparison to Ag@ Pec70 NPs that yielded $-12 \pm 3 \mathrm{mV}$ under similar conditions. The more negative ZP of Ag@Pec NPs could be attributed to a higher surface adsorption of $\mathrm{OH}$ - ions when NPs are synthesized at room temperature.

Incubation of the NPs with FBS during 30 min caused the $\mathrm{ZP}$ of $\mathrm{Me} @ \mathrm{Pec} \mathrm{NPs}$ to become more neutral ranging from -11 to $-2 \mathrm{mV}$. Moreover, the exposure of Me@Pec NPs to serum leads to reduction in the intensity of the 9 and $50 \mathrm{~nm}$ centered FBS's typical peaks (see Figure S1 in Supporting Information). These results could be related to the adsorption of serum proteins forming a biomolecular corona on the silver and gold NPs' surface when the particles come into contact with FBS, finding that is in good agreement with previous reports. $^{27,28}$ In particular, it was demonstrated that precoating pectin-capped copper sulfide NPs $(\mathrm{pCuS})$ with BSA produced a PC. ${ }^{29}$ Because Au@Pec NPs and Ag@Pec NPs have the same capping as $\mathrm{pCuS}$ and exhibit similar negative $\mathrm{ZP}$, formation of $\mathrm{PC}$ is also expected when they are in contact with FBS. The resulting entities could be suitable for in vivo biomedical applications because the approximately neutral surface charge is compatible with an adequate permeation of the NPs through cellular membranes without disrupting them. ${ }^{30}$

2.2. Cytotoxicity Assays. In order to evaluate cytotoxicity, 3-(4,5-dimethylthiazol-2-yl)-2,5-diphenyltetrazolium bromide (MTT) assays were performed with nonirradiated HeLa cells that had been cultured in low serum (LS)- or HSsupplemented minimum essential media (MEM) either with $1 \mu \mathrm{M} \mathrm{Me} @ P e c$ NPs, $50 \mu \mathrm{M}$ Rf or with preincubated Rf/Me@ Pec NPs. The obtained cell viability values evidenced that, under our experimental conditions, neither Me@Pec NPs, Rf nor preincubated Rf/Me@Pec NPs had an inherent adverse 

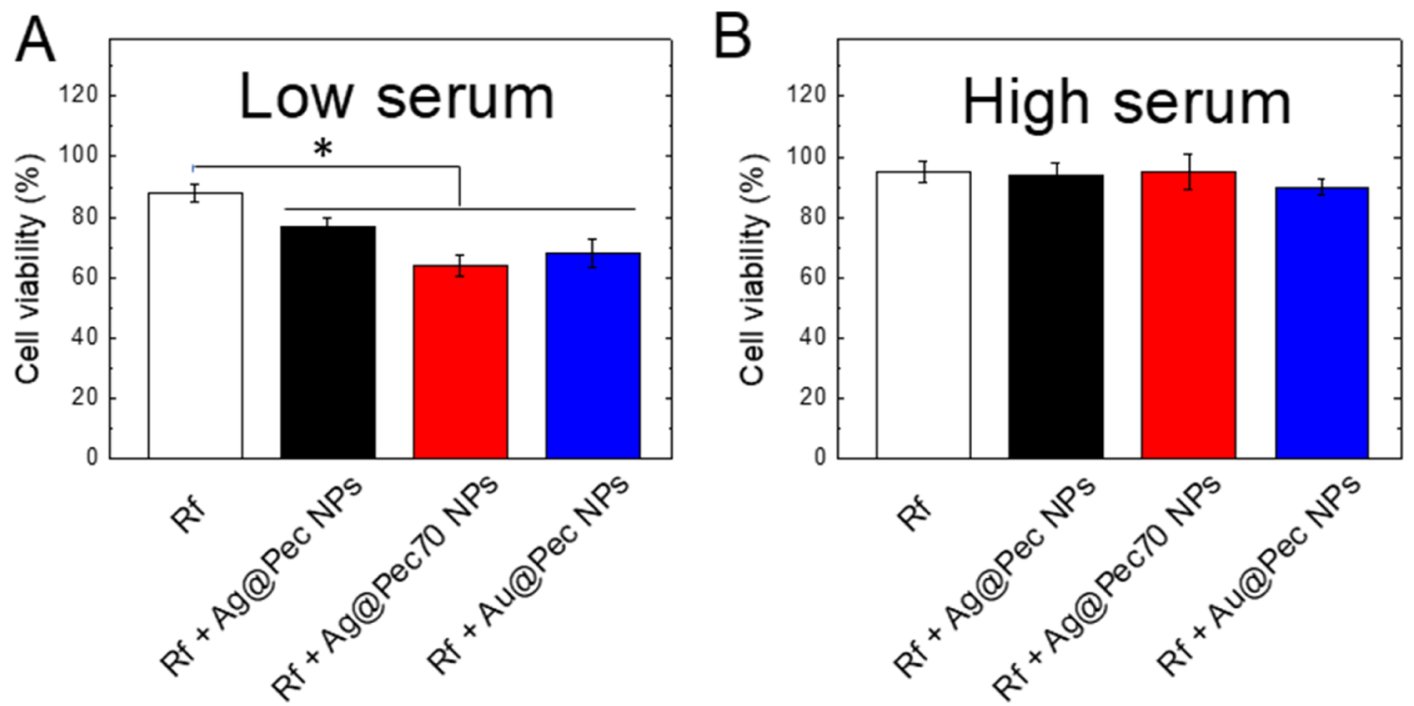

Figure 4. Bar graphs showing the results of the MTT assays on irradiated HeLa cells incubated in (A) LS- or (B) HS-supplemented MEM in the presence of Rf or Rf + Me@Pec NPs (Ag@Pec NPs-black-, Ag@Pec70 NPs-red-,or Au@Pec NPs-blue-). All data are presented as mean \pm SE from four to eight independent experiments $(* p<0.05$, one-way ANOVA with Tukey's post hoc test.).
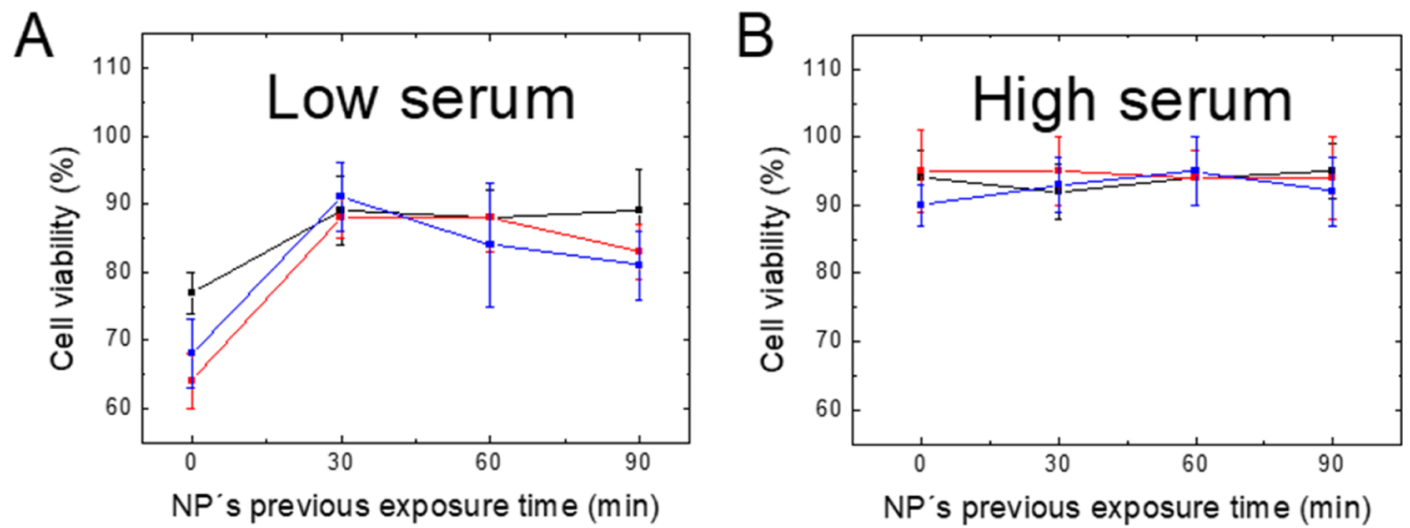

Figure 5. Viability of irradiated HeLa cells incubated with Rf + Me@Pec NPs that have been exposed during different incubation times to (A) LSor (B) HS-supplemented MEM (Ag@Pec NPs-black-, Ag@Pec70 NPs-red-, or Au@Pec NPs-blue-). All data are presented as mean \pm SE from four to eight independent experiments.

effect on HeLa cells independently of the serum concentration (Figure S2 in Supporting Information).

2.3. Effect of Me@Pec NPs in Rf-Based PDT. In this work, we performed phototoxicity assays in HeLa cells that have been cultured in two very different serum concentrations: a LS content corresponding to standard cell cultures and a HS content that better resembles protein concentration in blood. In order to evaluate if the basal cellular viability after irradiation in these two conditions is comparable, cell survival was assessed by the MTT assay. The mean values of formazan absorbance of irradiated cells cultured under LS and HS conditions and obtained from the same cellular batch were analyzed by analysis of variance (ANOVA). The ANOVA did not yield any statistically significant difference between HeLa cells' viability in LS- or HS-supplemented media after irradiation. From here, the results of the phototoxicity assays under LS or HS conditions will be referred as the percentage of viability respect to the mean formazan absorbance obtained in LS or HS control experiments (HeLa cells cultured without Rf and/or NPs).

Phototoxicity assays based only on Rf (white bars in Figure 4) caused a decrease in the cell's viability in comparison to the control experiments, as verified by the statistically significant difference between these measurements. A remarkable difference in PDT's efficacy is observed between the phototoxicity assays performed in LS- and HS-supplemented MEM (cell viabilities of 88 and 95\%, respectively), which could be associated with a lower $\mathrm{Rf}$ uptake due to a blockage of the specific transporters by serum proteins and/or to a higher photobleaching of $\mathrm{Rf}$ by intracellular proteins under $\mathrm{HS}$ conditions.

The addition of Me@Pec NPs together with Rf to LSsupplemented MEM cell cultures resulted in an enhancement of the basal effect of Rf-PDT as the cell's viability after irradiation is even more reduced, reaching values of 64 and 68\% viabilities for Ag@Pec70 NPs and Au@Pec NPs (red and blue bars in Figure 4a, respectively). Moreover, the enhancement effect in Rf-based PDT of these two NPs is better than that obtained with Ag@Pec NPs ${ }^{24}$ (77\% viability) as verified by the statistically significant difference between the measurements. In all cases, the enhancement effect can be understood in terms of the presence of Rf and Me@Pec NPs in the same intracellular microenvironment, as a result of the cellular internalization of Rf and Me@Pec NPs or the complex Rf- 

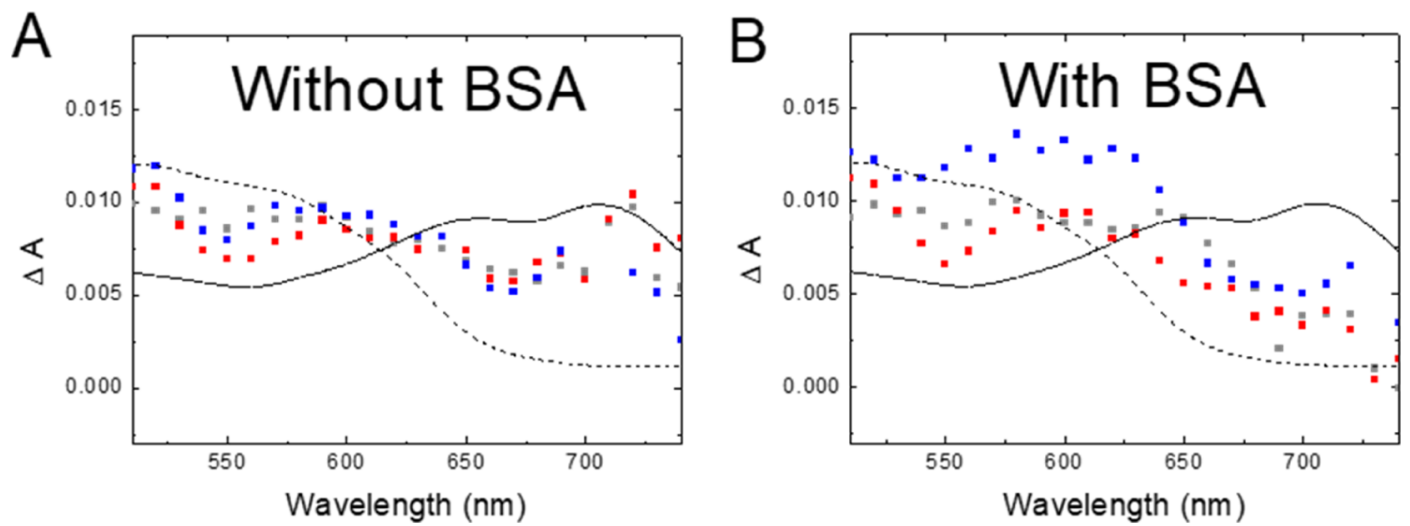

Figure 6. Transient absorption spectra taken $10 \mathrm{~ns}$ after the laser shot for Ar-saturated (A) $50 \mu \mathrm{M}$ Rf (grey), $50 \mu \mathrm{M} \mathrm{Rf}+1 \mu \mathrm{M} \mathrm{Ag} @ \mathrm{Pec} 70 \mathrm{NPs}$ (red), and $50 \mu \mathrm{M} \mathrm{Rf}+1 \mu \mathrm{M} \mathrm{Au} @ P e c$ NPs (blue) and (B) $50 \mu \mathrm{M} \mathrm{Rf}+2 \mu \mathrm{M}$ BSA (grey), $50 \mu \mathrm{M} \mathrm{Rf}+1 \mu \mathrm{M} \mathrm{Ag@Pec70} \mathrm{NPs}+2 \mu \mathrm{M}$ BSA (red), and $50 \mu \mathrm{M} \mathrm{Rf}+1 \mu \mathrm{M}$ Au@Pec NPs $+2 \mu \mathrm{M}$ BSA (blue). Solid and dashed black lines show the reported spectra for ${ }^{3} \mathrm{Rf}^{*}$ and HRf, respectively, from the study of $\mathrm{Li}$ et al. ${ }^{36}$

$\mathrm{Me} @ \mathrm{Pec}$ NPs, as previously found by our group for Ag@Pec NPs. ${ }^{24}$ The beneficial effect of Au@Pec NPs on PDT has not been previously reported. However, we have recently demonstrated $^{31}$ that photodynamic inactivation of bacteria mediated by Rf was enhanced in the presence of Au@Pec NPs due to the photoinduced generation of $\mathrm{Au}^{3+}$ ions. Because $\mathrm{Au}(\mathrm{III})$ species were reported to possess anticancer activity, the enhanced PDT effect observed in our experiments can also be assigned to $\mathrm{Au}^{3+}$ ions. ${ }^{32}$

Nevertheless, no beneficial effect of Me@Pec NPs on Rfbased PDT is observed in HeLa cells cultured in the HSsupplemented medium, evidencing that the negative impact of the higher amounts of serum proteins on the efficacy of photodynamics prevails over the possibility of the plasmonic NPs to enhance PDT.

2.4. Effect of Me@Pec NPs Preincubated with Serum in Rf-Based PDT. In order to investigate if the preincubation of Rf and Me@Pec NPs with serum affects the efficacy of PDT, NPs and Rf were exposed to LS- and HS-supplemented MEM during different incubation times before phototoxicity assays in HeLa cell cultures.

When Rf and $\mathrm{Me} @ \mathrm{Pec}$ NPs are preincubated under LS conditions (even after short exposure times), the enhancement of Rf-based PDT by the synthesized plasmonic particles disappears, as it can be verified from the phototoxicity assays, where the cell viability (Figure 5A, 30, 60, and $90 \mathrm{~min}$ of incubation) returns to the values where no NPs were added (white bar in Figure 4A).

The different impact of NPs in Rf-based PDT when the particles are exposed to FBS before the cell culture $(30,60$, and 90 min of preincubation of NPs and FBS) or simultaneously with the cell culture ( $0 \mathrm{~min}$ of incubation time) could be assigned to a different identity of the proteins adsorbed on the NPs. In this regard, a time evolution has been reported for the PC's composition in which early low affinity proteins are slowly replaced with high affinity ones. ${ }^{33}$ Thus, if we consider that particle internalization events may occur on a time scale of several minutes, when cells, Rf and NPs, are put in contact simultaneously, the reversibility of the interactions that the NPs establish with low affinity serum proteins could lead to a possible protein desorption prior to the contact of the particles with the cell membranes. ${ }^{34}$ However, when Me@Pec NPs are previously incubated with serum, proteins are more likely to be strongly bound to the NPs, thus affecting the particles' internalization. In this line, it was reported a reduction of polymeric NP uptake by HeLa cells' as a result of a PC formation. ${ }^{19}$ Moreover, the possible decrease of PDT's efficiency due to the presence of residual adsorbed proteins ${ }^{35}$ in the internalized Me@Pec NPs could affect the photophysics of the PS, a fact that cannot be discarded. In this line, it was verified that specific proteins present in the original PC are retained on the NPs after cellular uptake exhibiting different intracellular processing compared to what is observed when they are transported freely from the extracellular medium. ${ }^{35}$

Preincubation of Me@Pec NPs under HS conditions does not improve the efficacy of Rf-based PDT, as it can be verified from the high and constant cell viability after irradiation of HeLa cells (Figure 5B). This finding reinforces the idea that HS conditions block the uptake of NPs or negatively affect the ROS production by Rf.

2.5. Role of Proteins on the Transient Absorption Spectroscopy of Rf. Phototoxicity assays revealed the fundamental role of protein concentration in the efficacy of PDT. Herein, we have performed photochemical experiments by nanosecond laser flash photolysis (LFP) to analyze the effect of BSA on the photophysics of Rf and Rf/Me@Pec NP solutions.

Rf-based PDT efficacy relies on the production of the triplet excited state of $\mathrm{Rf}\left({ }^{3} \mathrm{Rf}^{*}\right)$ after irradiation as the precursor of the ROS necessary to produce photodamage. However, detection of the absorption of ${ }^{3} \mathrm{Rf}^{*}$ is not straightforward because its spectrum overlaps with those from the radical cation $\left(\mathrm{Rf}^{\bullet+}\right)$ and the neutral radical $\left(\mathrm{HRf}^{\bullet}\right)$ of the flavin, ${ }^{36}$ species that appear from Reactions 1 and 2

$$
\begin{aligned}
& { }^{3} \mathrm{Rf}^{*}+\mathrm{Rf} \rightarrow \mathrm{Rf}^{\bullet+}+\mathrm{Rf}^{\bullet-} \\
& \mathrm{Rf}^{\bullet-}+\mathrm{H}^{+} \leftrightarrows \mathrm{HRf}^{\bullet}
\end{aligned}
$$

where $\mathrm{Rf}$ and $\mathrm{Rf}^{-}$-represent the basal state and the radical anion of the flavin, respectively.

Figure 6A shows the absorption spectra for $\mathrm{Rf}$ and $\mathrm{Rf}+$ $\mathrm{Me} @$ Pec NPs without BSA taken $10 \mathrm{~ns}$ after the laser pulse together with the reported absorption spectra of ${ }^{3} \mathrm{Rf}^{*}$ and HRf. ${ }^{36}$ The contribution of ${ }^{3} \mathrm{Rf}^{*}$ to the experimental data is clear.

When BSA is put together with Rf or Rf + Me@Pec NPs, a smaller amount of ${ }^{3} \mathrm{Rf}^{*}$ with respect to $\mathrm{HRf}^{\circ}$ is observed (Figure 6B). This result is in excellent agreement with the 

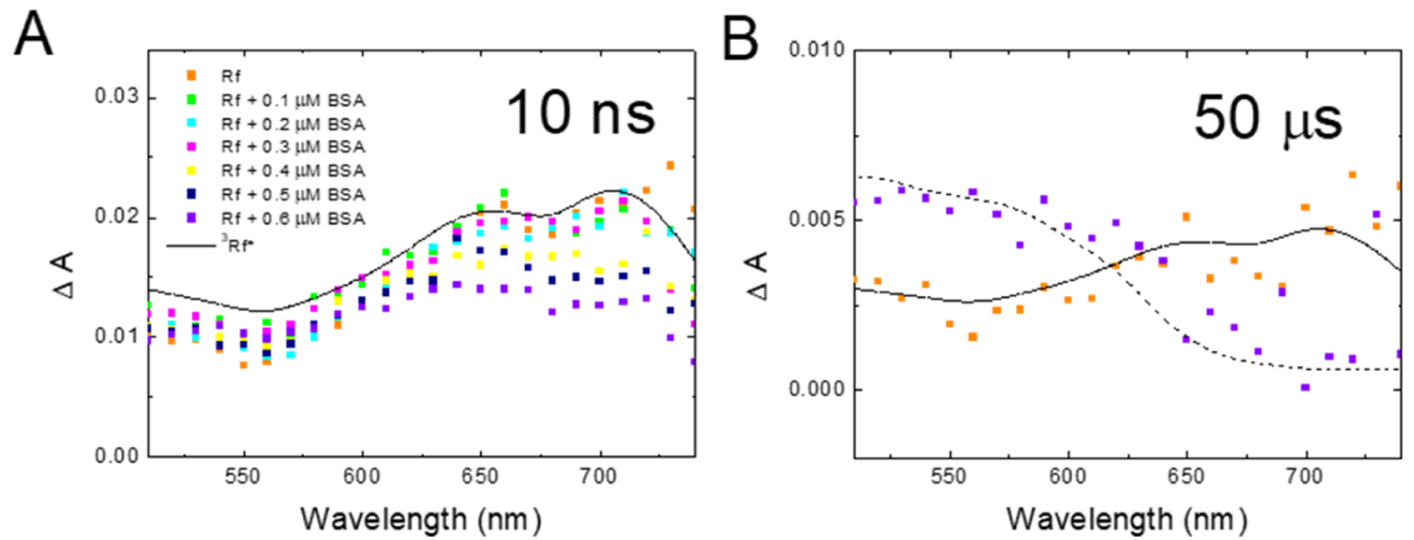

Figure 7. (A) Transient absorption spectra taken $10 \mathrm{~ns}$ after the laser shot for Ar-saturated samples containing $50 \mu \mathrm{M}$ Rf and BSA in the range from 0 to $0.6 \mu \mathrm{M}$ as indicated. (B) Transient absorption spectra taken $50 \mu \mathrm{s}$ after the laser shot for Ar-saturated samples containing $50 \mu \mathrm{M}$ Rf in the absence (orange) and in the presence (purple) of $0.6 \mu \mathrm{M}$ BSA. Solid and dashed lines show the reported spectra for ${ }^{3} \mathrm{R} f^{*}$ and HRf respectively, from the study of $\mathrm{Li}$ et $a .^{36}$

reported quenching of ${ }^{3} \mathrm{Rf}^{*}$ by BSA, which takes place by an electron transfer reaction from BSA to the excited state of the flavin, as shown in Reaction 3. ${ }^{37}$

$$
{ }^{3} \mathrm{Rf}^{*}+\mathrm{BSA} \rightarrow \mathrm{BSA}^{\bullet+}+\mathrm{Rf}^{\bullet-}
$$

where $\mathrm{BSA}^{\bullet+}$ represents a semioxidized species of the protein. Once $\mathrm{Rf}^{--}$is formed, it rapidly protonates (Reaction 2 ), and for that reason, we observe formation of HRf in samples containing BSA. This reaction is expected to take place within a noncovalent and relatively weak ground state complex between Rf and BSA, whose existence was evidenced by UVvisible absorption, fluorescence, and circular dichroism spectroscopies. ${ }^{37}$

From these results, it can be inferred that the amount ${ }^{3} \mathrm{Rf}^{*}$ available as a precursor of ROS involved in PDT is significantly affected by BSA and that when Me@Pec NPs are used as an additive in order to improve the performance of flavin sensitizers, the adsorbed proteins that are retained after the cellular uptake ${ }^{35}$ may play a negative role and $37-40^{29}$ in the intracellular ROS production affecting the efficacy of PDT. In this line, Subramaniyan showed that the antibacterial activity of pectin-coated $\mathrm{CuS}$ NPs upon irradiation decreased when a BSA PC is formed. ${ }^{29}$ These results in part can be explained by the inhibitory effect of the protein on the production of ROS. $^{29,37-40}$ Additionally, because of the electron transfer process (Reaction 3 ), both photoreduction of $\mathrm{Rf}$ and photooxidation of BSA were reported.

In order to further prove the occurrence of Reaction 3, we performed an additional series of experiments with $\mathrm{Rf}$ solutions containing lower amounts of BSA $(0-0.6 \mu \mathrm{M})$.

Figure 7A shows that the amount of ${ }^{3} \mathrm{Rf}^{*}$ present $10 \mathrm{~ns}$ after the laser shot decreases with the concentration of BSA in the samples, further confirming the reaction between ${ }^{3} \mathrm{Rf}^{*}$ with $\mathrm{BSA}$. Figure $7 \mathrm{~B}$ clearly shows that the spectra taken $50 \mu \mathrm{s}$ after the laser shot obtained in the absence of BSA (orange) are very similar to that reported for ${ }^{3} \mathrm{Rf}^{*}$, whereas in the presence of the protein (purple), formation of HRf is observed. This result indicates that at $50 \mu \mathrm{s}$ after the laser shot, most of the ${ }^{3} \mathrm{Rf}^{*}$ radicals were already reduced by BSA to yield $\mathrm{Rf}^{-}$(Reaction $3)$, which quickly protonates.

Considering that the ${ }^{3} \mathrm{Rf}^{*}$ quenching by a donor competes with quenching by oxygen and that the ${ }^{3} \mathrm{Rf}^{*}$ yield and decay kinetics depends on the protein/PS concentration, ${ }^{37}$ the major reason proposed for the sensitizer damage is electron transfer from the amino acids of a protein to ${ }^{3} \mathrm{Rf}^{*}$ in close vicinity, as was demonstrated for the enhanced photobleaching of flavins in the presence of different electron donors. ${ }^{41-44}$

\section{CONCLUSIONS}

In this paper, we analyzed the efficacy of Rf-based PDT in two very different concentrations concerning serum conditions: the low amount of serum that is commonly used in standard cell culture medium and a higher serum concentration that better resembles the biological environment that the PS and NPs encounter in vivo. Our experiments revealed a marked reduction in Rf-based PDT efficacy (with or without the assistance of NPs) when cells were cultured in more concentrated serum medium compared to the standard conditions, even when the basal viability was independent of the serum content.

The beneficial effect of Ag@Pec70 and Au@Pec NPs in Rfbased PDT on HeLa cells cultured under standard serum conditions was demonstrated for the first time. However, the preincubation of the NPs with serum avoids the possibility of the particles to enhance Rf-based PDT, finding that can be ascribed to the time evolution of the adsorbed proteins onto the NPs or to a diminution in the intracellular ROS production by action of the adsorbed proteins that are retained intracellularly. In regard to the latter point, we demonstrated that the deleterious effect of serum in the efficacy of PDT could be related to lower amounts of the triplet excited state of the PS under more concentrated protein conditions that leads to a lower production of the ROS necessary for the photodamage.

In summary, we verified that protein concentration has a determinant role in the efficacy of photodamage. Our findings point out the relevance of designing in vitro cell culture experiments for the development of new PS or PS/NP strategies under more realistic conditions, in terms of serum concentration, that resemble the biological environment where they would exert its therapeutic action in clinical PDTs.

\section{EXPERIMENTAL SECTION}

4.1. Materials. Rf, pectin from apple, tetrachloroauric acid, MTT, and BSA (MW $=66.5 \mathrm{kDa}$ ) were purchased from Sigma-Aldrich (St. Louis, Mo, USA). Silver nitrate was 
obtained from Biopack, sodium hydroxide from J.T. Baker, FBS from Internegocios S.A, and MEM and Dulbecco's modified Eagle medium: Nutrient Mixture F-12 (DMEM/ F12) from Gibco. All experiments were performed with MilliQ water.

Phosphate buffered saline (PBS) solution was prepared from potassium chloride, sodium chloride, sodium dihydrogen phosphate, and disodium hydrogen phosphate obtained from J.T. Baker (Pasadena, Ca, USA).

4.2. Me@Pec NP Synthesis and Incubation with Serum Solutions. Pectin-coated silver NPs (Ag@Pec NPs) were synthesized with a protocol adapted from the literature. ${ }^{45}$ In brief, an aqueous solution containing $10 \mathrm{~g} / \mathrm{L}$ of pectin was prepared by heating at $70{ }^{\circ} \mathrm{C}$ for about $2 \mathrm{~h}$ in order to ensure complete solubilization. After cooling it at room temperature, aqueous $0.1 \mathrm{M} \mathrm{AgNO}_{3}$ and $\mathrm{NaOH}$ solutions (1 and $25 \mathrm{mM}$ final concentrations, respectively) were added rapidly to the pectin solution under vigorous stirring. The reaction mixture was gently stirred at room temperature for $24 \mathrm{~h}$. The procedure described before but adding $\mathrm{AgNO}_{3}$ and $\mathrm{NaOH}$ solutions when the solution was still at $70{ }^{\circ} \mathrm{C}$, yielded the NPs called Ag70@Pec NPs. These synthesis conditions maximize the concentration of reducing sugars involved in the redox reaction between silver ions and pectin macromolecules. ${ }^{46}$

The synthesis of pectin-coated gold NPs (Au@Pec NPs) began with the preparation of $5 \mathrm{~g} / \mathrm{L}$ pectin aqueous solution by heating at $80{ }^{\circ} \mathrm{C}$ for about $2 \mathrm{~h}$. Then, $1 \mathrm{mM} \mathrm{HAuCl}{ }_{4}$ and the pectin aqueous solutions (final concentrations $0.1 \mathrm{mM}$ and 0.5 $\mathrm{g} / \mathrm{L}$, respectively) were added rapidly to Milli-Q water under vigorous stirring at $80{ }^{\circ} \mathrm{C} .{ }^{47}$ The synthesis was finished when the colourless solution turned to pink.

Rf and Me@Pec NPs were incubated under low- and highserum conditions before their addition to HeLa cells' cultures. Briefly, $50 \mu \mathrm{M}$ Rf and Me@Pec (Ag@Pec, Ag@Pec70, or Au@ Pec) NPs containing $\mathrm{Au}$ or $\mathrm{Ag}$ in the concentration $1 \mu \mathrm{M}$ were dispersed in MEM supplemented roughly with $50 \mathrm{mg} / \mathrm{mL}$ (HS) or $10 \mathrm{mg} / \mathrm{mL}$ (LS) FBS at $37{ }^{\circ} \mathrm{C}$ and subsequently incubated during $0,30,60$, or $90 \mathrm{~min}$. LS- and HS-MEM including Rf and Me@Pec NPs preincubated during different periods of time were used to culture HeLa cells $24 \mathrm{~h}$ before the cytotoxicity or phototoxicity assays.

4.3. Dynamic Light Scattering and ZP Measurements. The as-prepared NP suspensions were $1 / 1000$ diluted in deionized water and placed in polystyrene cuvettes or capillary cells with a path length of $10 \mathrm{~mm}$. Dynamic light scattering and ZP measurements were performed in triplicate using a Nano ZS Zetasizer (Malvern Instruments Corp, UK) at $25^{\circ} \mathrm{C}$. The same procedure was followed to measure NP suspensions that had been incubated for $30 \mathrm{~min}$ with FBS (1:1).

4.4. Transmission Electron Microscopy. NPs were diluted two times with deionized water or FBS (the serumcontaining samples were incubated for $30 \mathrm{~min}$ ), and a drop of the dispersion was spread onto carbon-coated 300-mesh copper grids. In order to achieve contrast enhancement, one drop of phosphotungstic acid was added to the dispersion. Micrographs were obtained with a Zeiss EM 109T transmission microscope, and images were analyzed with ImageJ software (free downloaded from NIH, USA). Particle diameters were determined, assuming that the particle area obtained from TEM micrographs was the projection of a spherical particle.

4.5. UV-vis NIR Spectroscopy. The as-prepared Me@ Pec NPs were studied by UV-vis NIR spectroscopy by means of a LAMBDA 35 spectrophotometer (Perkin Elmer). Additional spectra were recorded for Me@Pec NPs that had been exposed to FBS (1:1) for $30 \mathrm{~min}$.

4.6. Cytotoxicity Assay in the Dark. HeLa human cervical cancer cells $\left(1.5 \times 10^{4}\right)$ were plated in $100 \mu \mathrm{L}$ of $10 \%$ FBS-supplemented MEM and $100 \mu \mathrm{g} / \mathrm{mL}$ of penicillin and incubated overnight at $37{ }^{\circ} \mathrm{C}$ with $5 \% \mathrm{CO}_{2}$ until the desired confluence. The medium was then removed, and the cells were incubated for $24 \mathrm{~h}$ in LS- or HS-MEM, where Rf and Me@Pec NPs had been preincubated. Additionally, HeLa cell cultures including $50 \mu \mathrm{M}$ Rf or $1 \mu \mathrm{M}$ Me@Pec NPs were performed. Cell survival was assessed by the MTT assay as described previously, $^{24}$ and values of formazan absorbance were normalized against average values obtained from a control culture (cells to which neither Rf nor Me@Pec NPs had been added).

4.7. PDT Phototoxicity Assay. The procedure was the same as in the dark assay, and after the $24 \mathrm{~h}$ incubation, LS- or HS-MEM containing the preincubated Rf and Me@Pec NPs was removed and the cells were washed twice with PBS and DMEM/F12 without the addition of phenol red. Cell cultures were then irradiated using two RPR-3500A lamps. The emission of the lamps (Figure S3) is detailed in the Supporting Information. Illumination was conducted in a dark room, and the distance from the light source to the surface was $5 \mathrm{~cm}$. The irradiance measured using potassium ferrioxalate as an actinometer with the same irradiation geometry was $9.6 \mathrm{~mW}$ $\mathrm{cm}^{-2} \cdot{ }^{24}$ Cells were photoirradiated under these conditions for $2 \mathrm{~h}$ in order to obtain a decrease in HeLa cell viability, which could be easily detected by the MTT assay. ${ }^{24}$ Phototoxicity was evaluated by the MTT assay, and values of formazan absorbance were normalized against average values obtained from a control culture (irradiated cells to which neither $\mathrm{Rf}$ nor $\mathrm{Me} @$ Pec NPs had been added).

4.8. Transient Absorption Spectroscopy. Time-resolved measurements of photoinduced changes in the absorbance of the samples $(\Delta A)$ were made by means of LFP. Nanosecond LFP experiments were performed using the LP980 equipment from Edinburgh instruments. The third harmonic $(355 \mathrm{~nm})$ of a Continuum Surelite Nd:YAG laser (7 $\mathrm{ns}$ fwhm) was employed as an excitation source $(1 \mathrm{~Hz}, 10 \mathrm{~mJ} /$ pulse).

Argon-saturated aqueous samples including $50 \mu \mathrm{M}$ Rf, $1 \mu \mathrm{M}$ $\mathrm{Me} @ \mathrm{Pec}$ NPs, and/or BSA. BSA was chosen as a model protein because of its abundance in serum and its ability to interact with NPs, ${ }^{29,48}$ and the concentration $(0-0.6$ or $2 \mu \mathrm{M})$ was selected to ensure that the excitation light was mainly absorbed by Rf.

\section{ASSOCIATED CONTENT}

\section{(5) Supporting Information}

The Supporting Information is available free of charge at https://pubs.acs.org/doi/10.1021/acsomega.1c00542.

Size distribution by intensity obtained by DLS for Me@ Pec NPs in the presence and in the absence of FBS, MTT assays on non- irradiated HeLa cells and emission spectrum of the 8 RPR-3500 A lamps (PDF)

\section{AUTHOR INFORMATION}

\section{Corresponding Author}

Cecilia Y. Chain - Instituto de Investigaciones Fisicoquímicas Teóricas y Aplicadas (Facultad de Ciencias Exactas-UNLP- 
CONICET), 1900 La Plata, Argentina; ๑ orcid.org/00000002-8234-0556; Phone: 0054-221-425-7291 ext. 194;

Email: yamil@inifta.unlp.edu.ar; Fax: 0054-221-425-4642

\section{Authors}

José S. Cisneros - Instituto de Investigaciones Fisicoquímicas Teóricas y Aplicadas (Facultad de Ciencias Exactas-UNLPCONICET), 1900 La Plata, Argentina

María B. Rivas Aiello - Instituto de Investigaciones Fisicoquímicas Teóricas y Aplicadas (Facultad de Ciencias Exactas-UNLP-CONICET), 1900 La Plata, Argentina

Julieta Parisi - Instituto Multidisciplinario de Biología Celular (CICPBA-CONICET-UNLP), B1906APO La Plata, Argentina

Daniel C. Castrogiovanni - Instituto Multidisciplinario de Biología Celular (CICPBA-CONICET-UNLP), B1906APO La Plata, Argentina

Gabriela N. Bosio - Instituto de Investigaciones Fisicoquímicas Teóricas y Aplicadas (Facultad de Ciencias Exactas-UNLP-CONICET), 1900 La Plata, Argentina

Daniel O. Mártire - Instituto de Investigaciones Fisicoquímicas Teóricas y Aplicadas (Facultad de Ciencias Exactas-UNLP-CONICET), 1900 La Plata, Argentina; (-) orcid.org/0000-0001-9022-1904

María E. Vela - Instituto de Investigaciones Fisicoquímicas Teóricas y Aplicadas (Facultad de Ciencias Exactas-UNLPCONICET), 1900 La Plata, Argentina

Complete contact information is available at: https://pubs.acs.org/10.1021/acsomega.1c00542

\section{Notes}

The authors declare no competing financial interest.

\section{ACKNOWLEDGMENTS}

This work was supported by Consejo Nacional de Investigaciones Científicas y Técnicas (CONICET) (PIP 0671 and PUE 22920170100100CO), Universidad Nacional de La Plata (PID 11/X861), and Agencia Nacional de Promoción Científica y Tecnológica-Ministerio de Ciencia, Tecnología e Innovación Productiva (PICT 2016-0679, PICT 2016-0974, and PICT 2017-1628). J.S.C. and M.B.R.A. are postdoctoral fellows of CONICET. C.Y.C. and G.N.B. are members of the research career of CONICET. M.E.V. and D.O.M. are members of the research career of CIC PBA. Scheme ${ }^{1}$ and TOC graphic were created with BioRender.com.

\section{REFERENCES}

(1) van Straten, D.; Mashayekhi, V.; de Bruijn, H. S.; Oliveira, S.; Robinson, D. J. Oncologic photodynamic therapy: Basic principles, current clinical status and future directions. Cancers 2017, 9, 19.

(2) Castano, A. P.; Demidova, T. N.; Hamblin, M. R. Mechanisms in photodynamic therapy: part one-photosensitizers, photochemistry and cellular localization. Photodiagnosis Photodyn. Ther. 2004, 1, 279293.

(3) Lucky, S. S.; Soo, K. C.; Zhang, Y. Nanoparticles in Photodynamic Therapy. Chem. Rev. 2015, 115, 1990-2042.

(4) Huang, Y.-Y.; Sharma, S. K.; Dai, T.; Chung, H.; Yaroslavsky, A.; Garcia-Diaz, M.; Chang, J.; Chiang, L. Y.; Hamblin, M. R. Can nanotechnology potentiate photodynamic therapy? Nanotechnol. Rev. 2012, 1, 111-146.

(5) Krajczewski, J.; Rucińska, K.; Townley, H. E.; Kudelski, A. Role of various nanoparticles in photodynamic therapy and detection methods of singlet oxygen. Photodiagnosis Photodyn. Ther. 2019, 26, 162-178.
(6) Wang, C.; Zhang, X.; Liu, K.; Dai, X.; Yang, C.; Guo, S.; Su, H. Triplet Excited State Enhancement Induced by PDDA PolymerAssembled Gold Nanoparticles. J. Phys. Chem. C 2019, 123, 2771727724.

(7) Arakawa, T.; Munaoka, T.; Akiyama, T.; Yamada, S. Effects of Silver Nanoparticles on Photoelectrochemical Responses of Organic Dyes. J. Phys. Chem. C 2009, 113, 11830-11835.

(8) Barazzouk, S.; Kamat, P. V.; Hotchandani, S. Photoinduced Electron Transfer between Chlorophyll a and Gold Nanoparticles. J. Phys. Chem. B 2005, 109, 716-723.

(9) Adams, M.; Kozlowska, M.; Baroni, N.; Oldenburg, M.; Ma, R.; Busko, D.; Turshatov, A.; Emandi, G.; Senge, M. O.; Haldar, R.; Wöll, C.; Nienhaus, G. U.; Richards, B. S.; Howard, I. A. Highly Efficient One-Dimensional Triplet Exciton Transport in a PalladiumPorphyrin-Based Surface-Anchored Metal-Organic Framework. ACS Appl. Mater. Interfaces 2019, 11, 15688-15697.

(10) Planas, O.; Macia, N.; Agut, M.; Nonell, S.; Heyne, B. DistanceDependent Plasmon-Enhanced Singlet Oxygen Production and Emission for Bacterial Inactivation. J. Am. Chem. Soc. 2016, 138, 2762-2768.

(11) Giannini, V.; Fernández-Domínguez, A. I.; Heck, S. C.; Maier, S. A. Plasmonic Nanoantennas: Fundamentals and Their Use in Controlling the Radiative Properties of Nanoemitters. Chem. Rev. 2011, 111, 3888-3912.

(12) Caracciolo, G.; Farokhzad, O. C.; Mahmoudi, M. Biological Identity of Nanoparticles In Vivo: Clinical Implications of the Protein Corona. Trends Biotechnol. 2017, 35, 257-264.

(13) Ke, P. C.; Lin, S.; Parak, W. J.; Davis, T. P.; Caruso, F. A Decade of the Protein Corona. ACS Nano 2017, 11, 11773-11776.

(14) Shang, L.; Nienhaus, G. U. In Situ Characterization of Protein Adsorption onto Nanoparticles by Fluorescence Correlation Spectroscopy. Acc. Chem. Res. 2017, 50, 387-395.

(15) Partikel, K.; Korte, R.; Mulac, D.; Humpf, H.-U.; Langer, K. Serum type and concentration both affect the protein-corona composition of PLGA nanoparticles. Beilstein J. Nanotechnol. 2019, $10,1002-1015$.

(16) Francia, V.; Yang, K.; Deville, S.; Reker-Smit, C.; Nelissen, I.; Salvati, A. Corona Composition Can Affect the Mechanisms Cells Use to Internalize Nanoparticles. ACS Nano 2019, 13, 11107-11121. (17) Gan, N.; Sun, Q.; Zhao, L.; Tang, P.; Suo, Z.; Zhang, S.; Zhang, Y.; Zhang, M.; Wang, W.; Li, H. Protein corona of metal-organic framework nanoparticals: Study on the adsorption behavior of protein and cell interaction. Int. J. Biol. Macromol. 2019, 140, 709-718.

(18) Kennedy, D. C.; Gies, V.; Jezierski, A.; Yang, L. Changes in the physical properties of silver nanoparticles in cell culture media mediate cellular toxicity and uptake. J. Nanopart. Res. 2019, 21, 132.

(19) Gjuroski, I.; Girousi, E.; Meyer, C.; Hertig, D.; Stojkov, D.; Fux, M.; Schnidrig, N.; Bucher, J.; Pfister, S.; Sauser, L.; Simon, H.-U.; Vermathen, P.; Furrer, J.; Vermathen, M. Evaluation of polyvinylpyrrolidone and block copolymer micelle encapsulation of serine chlorin e6 and chlorin e4 on their reactivity towards albumin and transferrin and their cell uptake. J. Controlled Release 2019, 316, 150167.

(20) Yeo, E. L. L.; Cheah, J. U.-J.; Lim, B. Y.; Thong, P. S. P.; Soo, K. C.; Kah, J. C. Y. Protein Corona around Gold Nanorods as a Drug Carrier for Multimodal Cancer Therapy. ACS Biomater. Sci. Eng. 2017, 3, 1039-1050.

(21) Yeo, E. L. L.; Cheah, J. U.-J.; Neo, D. J. H.; Goh, W. I.; Kanchanawong, P.; Soo, K. C.; Thong, P. S. P.; Kah, J. C. Y. Exploiting the protein corona around gold nanorods for low-dose combined photothermal and photodynamic therapy. J. Mater. Chem. B 2017, 5, 254-268.

(22) Barile, M.; Giancaspero, T. A.; Leone, P.; Galluccio, M.; Indiveri, C. Riboflavin transport and metabolism in humans. J. Inherited Metab. Dis. 2016, 39, 545-557.

(23) Rivas Aiello, M. B.; Romero, J. J.; Bertolotti, S. G.; Gonzalez, M. C.; Mártire, D. O. Effect of Silver Nanoparticles on the Photophysics of Riboflavin: Consequences on the ROS Generation. J. Phys. Chem. C 2016, 120, 21967-21975. 
(24) Rivas Aiello, M. B.; Castrogiovanni, D.; Parisi, J.; Azcárate, J. C.; García Einschlag, F. S.; Gensch, T.; Bosio, G. N.; Mártire, D. O. Photodynamic Therapy in HeLa Cells Incubated with Riboflavin and Pectin-coated Silver Nanoparticles. Photochem. Photobiol. 2018, 94, 1159-1166.

(25) Yeo, E. L. L.; Cheah, J. U.-J.; Thong, P. S. P.; Soo, K. C.; Kah, J. C. Y. Gold Nanorods Coated with Apolipoprotein E Protein Corona for Drug Delivery. ACS Appl. Nano Mater. 2019, 2, 6220-6229.

(26) Glancy, D.; Zhang, Y.; Wu, J. L. Y.; Ouyang, B.; Ohta, S.; Chan, W. C. W. Characterizing the protein corona of sub-10 nm nanoparticles. J. Controlled Release 2019, 304, 102-110.

(27) Shannahan, J. H.; Lai, X.; Ke, P. C.; Podila, R.; Brown, J. M.; Witzmann, F. A. Silver nanoparticle protein corona composition in cell culture media. PLoS One 2013, 8, No. e74001.

(28) Maiorano, G.; Sabella, S.; Sorce, B.; Brunetti, V.; Malvindi, M. A.; Cingolani, R.; Pompa, P. P. Effects of Cell Culture Media on the Dynamic Formation of Protein-Nanoparticle Complexes and Influence on the Cellular Response. ACS Nano 2010, 4, 7481-7491.

(29) Subramaniyan, S. B.; Vijayakumar, S.; Megarajan, S.; Kamlekar, R. K.; Anbazhagan, V. Remarkable Effect of Jacalin in Diminishing the Protein Corona Interference in the Antibacterial Activity of PectinCapped Copper Sulfide Nanoparticles. ACS Omega 2019, 4, 1404914056.

(30) Clogston, J. D.; Patri, A. K. Zeta potential measurement. Methods Mol. Biol. 2011, 697, 63-70.

(31) Rivas Aiello, M. B.; Ghilini, F.; Martínez Porcel, J. E.; Giovanetti, L.; Schilardi, P. L.; Mártire, D. O. Riboflavin-Mediated Photooxidation of Gold Nanoparticles and Its Effect on the Inactivation of Bacteria. Langmuir 2020, 36, 8272.

(32) Sun, R. W.-Y.; Che, C.-M. The anti-cancer properties of gold(III) compounds with dianionic porphyrin and tetradentate ligands. Coord. Chem. Rev. 2009, 253, 1682-1691.

(33) Elechalawar, C. K.; Hossen, M. N.; McNally, L.; Bhattacharya, R.; Mukherjee, P. Analysing the nanoparticle-protein corona for potential molecular target identification. J. Controlled Release 2020, 322, 122-136.

(34) Liu, W.; Rose, J.; Plantevin, S.; Auffan, M.; Bottero, J.-Y.; Vidaud, C. Protein corona formation for nanomaterials and proteins of a similar size: hard or soft corona? Nanoscale 2013, 5, 1658-1668.

(35) Bertoli, F.; Garry, D.; Monopoli, M. P.; Salvati, A.; Dawson, K. A. The Intracellular Destiny of the Protein Corona: A Study on its Cellular Internalization and Evolution. ACS Nano 2016, 10, 1047110479.

(36) Li, H.; Melø, T. B.; Razi Naqvi, K. Triplets, radical cations and neutral semiquinone radicals of lumiflavin and riboflavin: An overhaul of previous pump-probe data and new multichannel absolute absorption spectra. J. Photochem. Photobiol., B 2012, 106, 34-39.

(37) Zhang, Y.; Görner, H. Flavin-sensitized Photo-oxidation of Lysozyme and Serum Albumin. Photochem. Photobiol. 2009, 85, 943948.

(38) Tapia, G.; Silva, E. Photo-induced riboflavin binding to the tryptophan residues of bovine and human serum albumins. Radiat. Environ. Biophys. 1991, 30, 131-138.

(39) Cardoso, D. R.; Franco, D. W.; Olsen, K.; Andersen, M. L.; Skibsted, L. H. Reactivity of Bovine Whey Proteins, Peptides, and Amino Acids toward Triplet Riboflavin as Studied by Laser Flash Photolysis. J. Agric. Food Chem. 2004, 52, 6602-6606.

(40) Zhao, H.; Ge, M.; Zhang, Z.; Wang, W.; Wu, G. Spectroscopic studies on the interaction between riboflavin and albumins. Spectrochim. Acta, Part A 2006, 65, 811-817.

(41) Edwards, A. M.; Silva, E. Effect of visible light on selected enzymes, vitamins and amino acids. J. Photochem. Photobiol., B 2001, 63, 126-131.

(42) Penzkofer, A.; Bansal, A. K.; Song, S.-H.; Dick, B. Fluorescence quenching of flavins by reductive agents. Chem. Phys. 2007, 336, 1421.

(43) Görner, H. Oxygen uptake after electron transfer from amines, amino acids and ascorbic acid to triplet flavins in air-saturated aqueous solution. J. Photochem. Photobiol., B 2007, 87, 73-80.
(44) Hirakawa, K.; Yoshioka, T. Photoexcited riboflavin induces oxidative damage to human serum albumin. Chem. Phys. Lett. 2015, 634, 221-224.

(45) de Melo, L. S. A.; Gomes, A. S. L.; Saska, S.; Nigoghossian, K.; Messaddeq, Y.; Ribeiro, S. J. L.; de Araujo, R. E. Singlet Oxygen Generation Enhanced by Silver-Pectin Nanoparticles. J. Fluoresc. 2012, 22, 1633-1638.

(46) Zahran, M. K.; Ahmed, H. B.; El-Rafie, M. H. Facile sizeregulated synthesis of silver nanoparticles using pectin. Carbohydr. Polym. 2014, 111, 971-978.

(47) Nigoghossian, K.; dos Santos, M. V.; Barud, H. S.; da Silva, R. R.; Rocha, L. A.; Caiut, J. M. A.; de Assunção, R. M. N.; Spanhel, L.; Poulain, M.; Messaddeq, Y.; Ribeiro, S. J. L. Orange pectin mediated growth and stability of aqueous gold and silver nanocolloids. Appl. Surf. Sci. 2015, 341, 28-36.

(48) Gnanadhas, D. P.; Ben Thomas, M.; Thomas, R.; Raichur, A. M.; Chakravortty, D. Interaction of silver nanoparticles with serum proteins affects their antimicrobial activity in vivo. Antimicrob. Agents Chemother. 2013, 57, 4945-4955. 